\title{
Disintermediation in Business-to-Business Service Channels: Mechanisms and Challenges
}

\author{
Fredrik Nordin, Danilo Brozovic and Maria Holmlund \\ Accepted for publication in Journal of Business-to-Business Marketing
}

\begin{abstract}
Purpose: The aim of this paper is to delineate a number of different disintermediation mechanisms within the context of business-to-business service channels and to identify the specific challenges associated with adopting these mechanisms.

Methodology: The research was conducted in accordance with abductive reasoning, moving continuously between the empirical world of four industrial (B2B) firms and the model world.

Findings: This paper delineates a choice of six disintermediation mechanisms and their attendant challenges within the context of industrial service channels.

Contribution: The paper provides an original conceptualization of disintermediation, which is detached from the traditional understanding of the concept. As such, it constitutes a useful starting point for the development of a formal theory of disintermediation.

Implications for practice: This paper should be useful for practitioners, because it presents various disintermediation options available to industrial firms faced by undesired intermediaries in their industrial service channels.
\end{abstract}

Keywords: service, disintermediation, industrial marketing, intermediaries, servitization 


\section{Disintermediation in Business-to-Business Service Channels: Mechanisms and Challenges}

\section{Introduction}

"Can you help us analyze how to handle the intermediaries and service companies between us and the end customers in our marketing channel? We are gradually becoming downgraded to a low-cost provider without any contact with our former customers. Our knowledge and skills are not taken into consideration anymore. We don't want to end up in the commodity hell."

This excerpt from a recent discussion with the managers of a leading producer of industrial goods and services in the specialized tools industry emphasizes how strongly business-to-business firms can feel threatened by various kinds of intermediaries or thirdparty actors entering between them and their end customers and captures the essence of the debate that prompted the research reported in this paper. This is an issue of great practical importance for many firms and one that is underrepresented in academic research, namely the challenges of dealing with service intermediaries gaining or holding a strategic position in market channels (cf. Grönroos 2007: 435-436). Specifically, this refers to external organizations that sell products and offer service and support to one or more producers.

The commoditization of technologies and the entry of competitors from low-cost countries into various industries, including automotive (Karlsson 2003), electro-technical (Davies 2004), construction (Rangan and Bowman 1992), and health care (Mittermeyer, Njuguna, and Alcock 2011) have made product competition increasingly intense. Offering additional services and solutions can remedy this situation, through providing non-pricebased valued added to customers (Matthyssens and Vandenbempt 2008, Paiola, Gebauer, and Edvardsson 2012), resulting in higher profit margins (Stremersch, Wuyts, and Frambach 2001). However, these developments have also paved the way for intermediaries (e.g., systems integrators and other service companies) between customers and the producers of goods and services. These actors may decrease the profit margins for producers. Consequently, producers have fewer options for developing their businesses (Karlsson 2003, Nordin 2005), leading them to reposition themselves as providers of value-added services. Although having intermediaries in market channels can constitute an important asset, enabling companies to reach and service their end-customers more effectively (Chung, Chatterjee, and Sengupta 2012), it may also increase the distance to customers. This "thirdparty threat" (Grönroos 2007: 435) may therefore negatively influence the producer's relationship with the customer (Tuli, Kohli, and Bharadwaj 2007, Åhlström and Nordin 2006). More generally, it can have negative consequences for the producer's adoption of service logic (Grönroos 2011, Grönroos and Helle 2010).

Despite the relevance of the topic, there is a lack of research focusing on alternative ways for business-to-business firms to handle undesired intermediaries in their market channels, i.e., to disintermediate. While disintermediation has previously been defined as, "by-passing" (Walters 2008), "cutting loose from" (Dutta, Sarmah, and Goyal 2010), or "the elimination of" (Huizingh 2002) traditional intermediaries, our perspective is different, in that we consider not only the removal of intermediaries, but also as reversing the problems that are caused by a third-party barrier between producer and end customer. We therefore define disintermediation slightly more generally, as an organization's adoption of various mechanisms for handling intermediaries, aimed at securing links with end customers. Those mechanisms are regarded as different means of countering the problems of various third-party 
threats that prevent a constructive relationship with the end customer. This definition implies extending the previous literature on disintermediation that usually focuses on the introduction of Internet sales channels (Lancioni, Smith, and Oliva 2000, Shapiro, Romano, and Mittal 2004).

More specifically, the main aim of this paper is to delineate a number of different disintermediation mechanisms that may be adopted by business-to-business firms in the context of their service channels. The work entails six options: (1) strategic partnering, (2) mergers and acquisitions, (3) organic growth, (4) communication and training, (5) incentives, and (6) information and communication technology. The second objective is to identify the specific challenges associated with adopting these mechanisms, and which may prevent customer links from being secured.

The remainder of the paper is organized as follows. The following section presents the empirical methodology. The data base is then presented, followed by the abductive analysis leading to the six propositions. The paper concludes with a summary of the main findings and a discussion of the implications for managers pressured by their intermediaries towards "commodity hell." Suggestions for future research are also provided.

\section{Methodology}

\subsection{Research design}

The research was conducted in accordance with abductive reasoning, moving continuously between the empirical and the model worlds (Dubois and Gadde 2002) and drawing on a combination of empirical data and literature, through a series of iterations in which theory and data are matched. The need for a model that would reveal mechanisms for and challenges of disintermediation arose during the initial discussions with company managers, after which the researchers reviewed the broader management and marketing literature to identify possible disintermediation mechanisms. The conceptualization of various mechanisms and the attendant challenges were then refined through subsequent cycles of data collection and literature reviews, thus expanding the researchers' understanding of both the theory and the empirical phenomena. This enabled the development of new theory (Dubois and Gadde 2002). A conceptual model of the research is presented in Fig. 1.

\section{Insert Figure 1 about here}

Qualitative data were gathered during a one-year longitudinal research study that examined the development of service offerings by four European-based multinational industrial producers from four different industries: Rotating Systems (RS), Smooth Units (SU), Sharp Machine Tools (SMT), and Smart Machines (SM) (pseudonyms have been used to protect the anonymity of the companies and the participants). The longitudinal approach enabled us to gather relatively detailed data (Yin 1994) and yielded a deep understanding of contextual factors and issues related to service channel structures.

The one-year time frame also established trust between researchers and informants, facilitating the collection of frank and reliable data on the challenges related to different disintermediation mechanisms. The duration of the engagement, together with constant the collaboration with company representatives, and the development of the model in interaction 
with the companies and through an iterative process merging the theory with the empirical findings, increased the credibility of the research study.

The four case companies promised more robust findings than would have been obtained from just one (Eisenhardt and Graebner 2007, Yin 1994). Similarities among the results from the cases also indicate that the findings are relevant beyond each individual case.

\subsection{Companies studied}

To develop our theory, four industrial producers from different industries were selected. They were regarded as appropriate cases, as they were working on a variety of disintermediation mechanisms and could thus provide data relating to the propositions on hand. The head offices of these companies were all located in Europe, and all were mature, market-leading, multinational, producers of relatively complex products. Although they had all been successful in their product-led businesses, the case companies had identified the provision of services and the adoption of service logic as the key strategy for future growth, implying increasing attempts to engage with processes creating value for customers. They had previously offered basic services, such as maintenance and the supply of spare parts, but all the firms had increasingly begun to focus on supporting their customers' value-creating processes and on developing and offering full services and solutions, such as outcome-based contracts and long-term rental agreements. These four producers thus represented a certain breadth of market, company size, strategy, and experiences from disintermediation. They had in common their struggle to handling service intermediaries in their marketing channels, which made them a suitable starting point for developing generalizable knowledge about disintermediation.

\subsection{Data collection and analysis}

Data were collected by means of five workshop discussions and 20 formal, semistructured group and individual interviews conducted with 1-3 respondents per interview. Twenty-seven respondents were directly involved in the project. Secondary data comprising company annual reports, information from company websites and internal documentation supplemented the primary data. Among the 27 respondents, five were employees at RS, three at SU, eight at SMT and six at SM. Five respondents were employed by two different intermediary firms - two from Loyal Distributor (LD) and three from Flexible Services (FS). The average duration of each interview was 1.5 hours, and the workshop length ranged from a half a day to two days. The respondents were selected because they were regarded as knowledgeable about the strategies and service business models of their respective firms. They held various different positions at their firms, ranging from service operations managers and service technicians to business development managers and salespeople. The workshop discussion and interviews focused on: (1) the strategy and business of the firms; (2) the structure of marketing channels; (3) present and previously experienced challenges related to the marketing channels; and (4) methods of handling these challenges. The preliminary results of the analysis were also discussed with the respondents during the subsequent workshops and interviews, and were gradually refined. Both the workshops and the interviews were recorded and transcribed. Sources of information also included several informal telephone calls with employees and company documents such as annual reports, organizational charts, and process descriptions.

In accordance with Eisenhardt (1989), the collective data from the in-depth interviews and workshops were analyzed by two of the authors, using a software-based tool for text 
analysis (Weft QDA) to identify material that supported the emerging model. Some incongruences were noted. The researchers also measured how much each problem was discussed during the interviews, to determine the relative importance of each challenge. This measure supplemented the more qualitative impressions, because counting enables researchers to remove doubts about the accuracy of their impressions of the data (Silverman 1993). Several times during this process, the results and tentative conclusions were presented and discussed with the company representatives, thus initiating a new round of data collection and literature analysis that allowed for a subsequent refinement of the emerging theory on disintermediation. The final output was read and discussed as a last check of the analytical process.

This longitudinal stepwise approach facilitated the gathering of detailed data and the gradual development of a deep understanding of the challenges inherent to different disintermediation mechanisms. Although such qualitative methods have acknowledged limitations, notably the difficulty of interpreting open-ended and often disorganized data (Kidd and Parshall 2000, Stewart and Shamdasani 1990), the procedures followed in the present study proved efficient and effective in gathering and analyzing the data. In addition, the method of several cycles of data collection and analysis ensures a high level of research dependability.

\section{The cases in the study}

A description of the study cases and central contextual factors, including a synopsis of the disintermediation problem and solution for each case, is presented below.

$R S$ provides relatively high-price and high-quality industrial products, including components for ventilation systems and escalators, and a comprehensive portfolio of services and solutions. RS is one of the largest global players in its target sectors, has existed for more than a century, and employs more than 2,000 workers in Sweden. Over the years, it has lost direct contact with its end customers in the property market to different third-party actors, e.g., service companies and distributors, thus acting as merely one sub-supplier among many. According to RS, the market is characterized by a lack of loyalty, excessive discounts, and low-price competitors. RS does not have the resources to visit its many end customers individually, and its loyal distributors cannot maintain this type of contact either, due to their limited contact with end customers. While the services offered by RS can potentially prolong the life of customers' products, and reduce energy consumption, thus saving their resources in the long term, such savings represent only about $10-20 \%$ of those customers' total expenditures. The disintermediation efforts of RS focus primarily on convincing potential customers and partners of the benefits of the new service.

$S U$ is a Finnish producer of high-quality industrial mechanical and electromechanical products, services and solutions. SU has approximately 150 employees and its customers are primarily companies in the processing industry, such as paper and pulp and industrial original equipment manufacturing. SU previously provided its simpler products and services through a network of distributors and its more complex services and systems directly. Unexpectedly, SU recently lost its direct contact with one of its major end customers in the paper and pulp industry, PaperCo, when this end customer decided to reduce its costs by outsourcing its service activities to a large, specialized full-service provider, namely Inexpensive Services (IS), due to financial problems. Thus, the interests shifted abruptly toward costs savings rather than value-creation mechanisms. SU's disintermediation efforts are primarily to establish a partnership with a more flexible company, Flexible Services, which can keep a lower service price. 
$S M T$ is a Swedish producer of specialized tools for various industries and related product services, employing 8,000 employees. SMT has always been very product-oriented. However, services have been included as an integral part of the offering and over time developed into more sophisticated solutions, which are often integrated into product offerings. SMT has always aimed at raising the productivity of its machines and thus benefiting its clients. Basic services have always been free of charge. To counter the perceived risk of being downgraded to a mere commodity supplier, SMT has developed a new software solution in the form of a software package library integrated into ComputerAided Manufacturing (CAM) software used by customers. The objective is to link up with, support, and influence both existing and potential customers. Their disintermediation solution also implies a need for increased collaboration with Computer-Aided Design (CAM) providers.

$S M$ is a leading producer of industrial robots and robotics and provides robot software, peripheral equipment, and related services. SM has approximately 3,000 employees, and its head office is located in Sweden. Its customers are spread over many industries, such as automotive and retail. SM's products and services are sold and distributed through a network of more than 100 resellers. Because of the perceived commoditization risk related to its robots, the associated entry of third-party actors in the channel, and the corresponding deterioration of RS' relationship with end customers, and the reduction in profits from its after-sales market due to improved robots reliability, SM has developed an ICT (information and communication technology) mechanism called "remote services" for its robots. This is based on sensors and mobile technology built into all robots, to monitor their current condition and plan preventive maintenance proactively and conduct repairs when needed. This service and the built-in technology could improve the company's understanding of how their customers use the robots, this information serving potentially as input to product and service development.

The main problems and primary disintermediation mechanisms of the different cases are summarized in Table I:

\section{Insert Table I about there}

\section{Results: Six disintermediation mechanisms}

Six main disintermediation mechanisms - (1) strategic partnering, (2) mergers and acquisitions, (3) organic growth, (4) communication and training, (5) incentives, and (6) information and communication technology, together with the corresponding challenges, can be summarized in the form of propositions. The companies in the study used these options, were considering using them, or had decided against them. A synopsis of the different disintermediation options and challenges associated with each option, grounded in the empirical data and previous literature, is presented in Table II below. In order to facilitate understanding, illustrative quotes from our study are also included in the table.

\section{Insert Table II about here}




\subsection{Strategic partnering}

In all four cases, to varying degrees, strategic partnering between the producer and one or more intermediaries further downstream in the marketing channel was evaluated as a means of maintaining optimal relationships with end customers. Establishing such relationships can enable the involved companies to achieve long-term strategic objectives and thus improve their competitive position (Mentzer, Min, and Zacharia 2000). Partnering with an intermediary in a producer's marketing channel can relatively quickly create or enhance value for the customer and thereby possibly restore a damaged relationship with the end customer (cf. Inkpen 1996, Ireland, Hitt, and Vaidyanath 2002). Furthermore, this can be achieved without investing in, integrating or administering internal organizational resources. Such relationships are based on mutual trust, openness, and shared risks \& rewards (Lambert, Emmelhainz, and Gardner 1996: 2).

Our empirical study also highlights the challenges of ensuring balanced interdependence (McDonald 1999), shared commitment, compatible goals (Gomes-Casseres 1998, Mentzer et al. 2000, Mohr and Spekman 1994), and cultural compatibility (Ellram 1990, Maloni and Benton 1997). In the case of SU and FS, for instance, the business philosophies of the two partner companies were compatible. As one respondent explained, "we met before and have very similar views on business. [...] I feel that we can trust each other". In contrast, it was not possible for SU to collaborate with IS, for the converse reasons. Respondents from our study also cited complementary know-how as a major issue, which has also been emphasized in the literature (e.g., Bleeke and Ernst 1995, Douma et al. 2000) as a critical success factor. In the case of SU and FS, there appeared to be a good match of competencies: "they have complementary skills, there is no conflict," one respondent from FS noted.

Another challenge in adopting a partnering mechanism is that the interests and actions of the different partner firms do not automatically converge, because the firms remain separate, with different identities and objectives. Partnering implies changes to the social systems of the firms, and other empirical evidence has shown that many partnering attempts fail or involve considerable tension and conflict (Boddy et al. 1998, Nordin 2006). There is also a comparatively high risk that each partner may act opportunistically (Williamson 1979).

Our empirical findings confirm the crucial role of interorganizational tension and the compatibility of the partners' organizational cultures, business philosophies, and know-how (Tate 1996). In the case of SM, the launch of a remote service was impeded by the limited focus on such services in the business philosophy of their resellers: "surprisingly, they are not so enthusiastic about the idea of selling remote services," complained one senior manager from SM, pointing to the importance of compatible goals and commitments. In summary, drawing on the empirical data and the literature, the following proposition can be offered:

P1: Strategic partnering is a disintermediation option based on developing an extended relationship with an intermediary and with a high level of cooperation. It requires the development of trust and overcoming challenges such as conflicting interests, incompatible know-how, cultural differences, and opportunism.

\subsection{Mergers and acquisitions}

Under some conditions, the development of partnerships and the associated adoption of informal governance mechanisms are not feasible. The internalization of the transaction by acquiring another company or establishing a joint venture can then be a more feasible 
disintermediation alternative, despite the initial costs. Logically, the viability of an acquisition increases with the financial strength of the potential buyer and the degree to which the transaction involves critical processes and resources that must be protected (Hoffman and Schaper-Rinkel 2001). While this disintermediation mechanism was considered by the organizations in our research, interestingly, the cost of disintermediation was not mentioned. This finding does not necessarily indicate that cost is not important in the context of mergers and acquisitions (M\&As), but rather reflects the good financial standing of the producers in our study. Even so, none had adopted this mechanism, although some have used it in the past. As one of the respondents emphasized: "The possibility of M\&As may not be feasible at this time, but this does not exclude its deployment as a strategic option in the future, if we find a company with a matching strategy that we can work with". M\&A thus seemed a less likely option for the companies involved in our research, since they regarded partnering as a more flexible option. One respondent stressed the importance of knowing exactly what you are buying: "if we buy them, what exactly do we buy?". Because of such uncertainties, the internalization of a transaction through an acquisition or joint venture may not be feasible in turbulent environments, in which more flexible arrangements, such as partnerships, are preferable (Hoffman et al. 2001).

As Harrigan (1988) noted, shared ownership and shared decision-making arrangements can be particularly cumbersome and may reduce the speed with which many global strategies can be implemented. Although the parties involved can renegotiate both the contractual agreements and joint ventures at any time, a joint venture is often considered more difficult to establish, terminate, and change than a contractual agreement (Harrigan 1988). Because both acquisitions and joint ventures imply the integration of two companies, the identification and exploitation of operational synergies and the creation of positive attitudes toward the integration among employees on both sides, are critical elements. In multinational joint ventures, differences between the home and host cultures may increase the effort and time required to establish a positive working relationship that bridges the gaps between cultural, linguistic, and organizational traditions (Anderson and Gatignon 1986).

An important challenge mentioned by several respondents is the difficulty for a producer to acquire only the specific part of the other company's business in which they are interested, rather than the entire company: "we are not interested in buying them because they have many activities that are not relevant to us," one respondent noted. He added: "buying them would imply a long-term commitment requiring a very good strategic fit". Despite the often lower strategic flexibility, as well as the time and costs involved in internalizing a transaction or developing a joint venture, where there is a significant degree of competition over a potential partner's resources, these options may assist in acquiring them (Dyer, Kale, and Singh 2004, Osborne and Baughn 1990). Hence, the following proposition:

P2: An M\&A is a disintermediation option that involves the purchase of or merger with an intermediary. It is a relatively costly disintermediation mechanism in terms of time, direct costs and integration costs and is best used when there is a good strategic and cultural fit between the partners and when a positive attitude toward the integration can be created.

\subsection{Organic growth}

Establishing a completely new intermediary organically in the market is another option for a producer wishing to bridge the gap caused by its existing intermediaries. None of the companies in our study had chosen this option of starting a new intermediary owned and controlled by them, but all had considered it and for various reasons selected other means of 
disintermediation. The main reasons mentioned were the relatively high costs and the importance of having appropriate resources, with the requisite skills and interests: "the greatest challenge lies in finding the appropriate resources and people who can deliver services" a respondent from RS noted and thus indicated that this option can be timeconsuming and uncertain. Companies opting for the organic growth of a new intermediary are thus likely to be large players, because creating a new company requires substantial financial resource (Roberts and Berry 1985).

By starting a new intermediary internally, a producer will logically have greater direct control over the new company, than over the existing external intermediaries. The producer may also want to expand its area of expertise or provide more value-added services. Thus, an organically developed intermediary can be feasible, if a producer recognizes a business opportunity (Ardichvili, Cardozo, and Sourav 2003, Shane 2000) or possesses knowledge and ideas which constitute a source of entrepreneurial opportunity (Audretsch and Keilbach 2007).

The literature also mentions disadvantages, most notably the mixed record of success (Roberts et al. 1985) of such endeavors. The possibility of success cannot be predicted reliably, because of the high rate of bankruptcies for (all) new companies (Ottesen and Grønhaug 2005) and success depends on a number of various individual factors, such as sufficient size and capital, or sufficient preparation (Honjo 2000, Schutjens and Wever 2000). Furthermore, survival also depends on the personality traits of the key individuals (Watson, Hogarth-Scott, and Wilson 1998), including their networks and contacts in the form of social capital (De Carolis, Litzky, and Eddleston 2009, De Carolis and Saparito 2006). Because success depends on the entrepreneurial talent of individuals, the producer's critical issue is to retain valuable individuals, and to avoid serving as an incubator of potential competition (Neck et al. 2004). Furthermore, the corporate climate may not be suitable for encouraging entrepreneurial initiatives (Roberts et al. 1985).

Most of the respondents in our study agreed that their industrial sectors are experiencing a disappearance of technical and technological knowledge and skills, which may limit the potential for incubating new intermediary companies. "They are not interested in such technical things anymore", one respondent commented. He further explained that youth are no longer interested in studying subjects related to industrial companies and their marketing activities, and industrial companies have already begun to face this challenge. This situation remains an important issue for further research, and further investigation may confirm this scenario. Accordingly, the following proposition can be formulated:

P3: Disintermediation through organic growth is a disintermediation option for companies wishing to develop a new intermediary internally, in order to promote direct contact with its customers. However, it is an uncertain, costly and time-consuming option that is best applicable when the producer is characterized by substantial knowledge, social capital, financial resources, and entrepreneurial individuals.

\subsection{Communication and training}

Although the communication of value propositions is only a small part of the overall value-creation process, with interactions during service delivery and the actual value fulfillment being equally important elements (Grönroos 2006), it can constitute an important element for organizations attempting to approach their end customers and bridge unwanted gaps caused by intermediaries. Accordingly, this was emphasized by all companies in our study. As new technologies have enabled increased interaction between companies and their 
customers (Duncan and Moriarty 1998), communication emerges as a particularly relevant element of marketing. Normann (2001) draws attention to the proliferation of new "access channels", such as the Internet and new media, together with increased knowledge and activity on the part of customers who themselves search actively for the best partners. There is also a tendency towards decreased customer loyalty, which poses new challenges for companies striving to maintain their customer relationships in an environment where competitors are attempting to usurp those relationships. As a manager from SMT put it: "the client needs more and more information; the product cycle has been reduced, more and more products keep getting changed, and everything has to be done more effectively. There is just a huge demand for more information." Essentially, this disintermediation option is about fundamental marketing techniques aimed at influencing the behavior of other parties. However, the respondents' answers suggest that this communication should be directed not only to the end customer, but also to the intermediary and even internally within the company.

A specific example of a communication effort mentioned by our participants concerns the training of intermediaries and customers. SU and RS emphasized that only through the appropriate training of resellers regarding installation and maintenance can their products achieve an optimal lifetime. What is more, communicating how best to handle their products increases the chances of the intermediaries treating the end customers appropriately. Because such training is not free of charge, the companies also earn decent profits. Furthermore, resellers often have to attend a series of training courses in order to receive the company authorization and the right to re-sell their products. "Training used to be free and then we decided to charge. The decision was controversial, but it turned out right in the long run; it ensured that the right kind of people attend the training," a manager from SU points out. One respondent remarked that, during such training, the companies also have the opportunity to draw attention to the flats of competitors' products. The literature confirms the benefits of the training. For instance, it can strengthen the relationship, ensure the proper installation of products, and provide relevant feedback to the company (Llopis, Gasco, and Gonzalez 2006).

A service focus also requires properly trained sellers and service employees. A company's employees control the critical factor of customer communication and thus, disintermediation through communication and training must involve employee training. Walsh, Evanschitzky and Wunderlich (2008) confirm that well-trained employees play a pivotal role in the development of customer loyalty. Normann (2000) states that the interactive process of service delivery depends on the service employee's skills and experiences, and also on customer expectations and behavior. "You cannot just dance in there, look around, and blurt out, 'oh, my, what a big machine.' You'll be gone, out of the picture. You have to talk the language they are talking, to show them you know what you are doing," one respondent from SU said, pointing to the relational and interactive character of the service-selling process (Tuli et al. 2007). Other study participants also discussed the issue of appropriately trained sellers, pointing out that selling services poses different challenges and demands a different mind frame than selling products (cf. Kindström, Kowalkowski, and Nordin 2012).

Besides the personnel issue, other communication and training challenges include the danger of communication inconsistency during relationship building (Andersen 2001), something confirmed indirectly by the participants, and drawbacks of the training method. The implementation of knowledge-based training can be difficult in terms of finding the time and appropriate methods to train employees effectively (Bowersox, Closs, and Stank 2000). This leads to the following proposition: 
P4: Disintermediation through communication and training is an option that is based on the exchange of information and instructions aimed at strengthening the relationship with intermediaries and customers, thereby influencing their reasoning, perceptions and actions. Challenges associated with this option are that it requires educated personnel, consistent communication and viable training methods.

\subsection{Incentives for intermediaries}

The fifth disintermediation mechanism drawn from our study refers to a company's creation of incentives that influence the intermediary to direct itself toward the products and services of this particular company. The intermediary is thus encouraged to focus on the products and services of that particular company and remain loyal to it. The respondents in our study emphasized the relevance of different types of incentives when offering services (e.g., financial and also more informal incentives, such as common goals and projects), also stating that offering service is an incentive itself. "The services part of the business is the incentive for our intermediaries, because it offers them more opportunities to earn revenue," states one of the respondents from SU. Other incentives mentioned by the respondents were superior products and a strong brand. In this respect, one respondent from FS mentioned that it is far easier to enter a new potential customer company backed with a strong brand which implies a high-quality product. The literature confirms that powerful incentives and benefits for the intermediary may also result from offering established brands (Glynn, Motion, and Brodie 2007). However, as the respondent commented, even if the brand is strong, a single individual's contact with a customer can still either undermine or strengthen the brand.

Focusing on incentives in marketing channel relationships, the literature sometimes distinguishes between unilateral (one-way) and bilateral (cooperative) incentives. According to Gilliland and Bello (2001), unilateral incentives are adopted when the goals of the included parties are not synchronized and include monetary payments, discounts, technical support, and bonuses to motivate the counterpart. Bilateral incentives are less formal and adopted when there is joint desire to continue the relationship, both parties focusing on a shared set of goals and with a significant degree of trust. An example of the latter among the cases in our study is RS and LD. As mentioned in the case description, LD was started organically by RS, they represent the latter's largest domestic distributor, and the business relationship operates in an open and cooperative manner in the context of mutual goals. "Here we have no secrets," said a manager from RS during an informal conversation prior visiting LD - "we talk freely in front of the LD management." However, LD remained reserved in helping RS because of unclear financial potential of the market. "If we want this market, we will naturally return," said a manager from LD. This quote also exemplifies the relevance of financial incentives for continuing the relationship (Johnson and Black 1996).

The companies in our study exhibit tendencies towards more collaborative relationships and bilateral incentives, but nevertheless mention that previously, they influenced some distributors unilaterally, although they try not to abuse the market position. "RS does not have the legal power, but we do have the social power," said one of the respondents. Also, some case companies deal exclusively with authorized intermediaries, which increases their power and makes the intermediary more dependent on the producer. At the same time, authorization is a mark of quality and reliability for the customer. The issue of inter-firm power inevitably surfaces and becomes evident - the company's ability to exercise power and positive incentives towards its distributors are strongly related (Glover 1991).

In the context of relationships, marketing power has often been criticized as having negative effects on channel relationships (for example, see Frazier 1999). However, "firms 
with power advantages will attempt to mold strong and effective relationships rather than pressuring associated firms to maximize selfish interests" (Frazier 1999: 228). Thus, the problem does not lie in the power itself, but rather in how it is used and with what purposes and intentions. The major drawback lies in the temptation to behave opportunistically, because such behavior can erode many of the relational elements necessary for the development $o$

f effective buyer-supplier relationships (Maloni and Benton 2000). Regardless of how a supply chain is structured, it will function well if its companies' incentives are aligned that is, if the risks, costs and rewards of conducting business are distributed fairly across the network (Narayanan and Raman 2004). Given the above literature and discussion, we formulate the following proposition:

P5: Disintermediation through incentives is an option involving the design of an appropriate set of incentives aimed at influencing the intermediary and its behavior. This option is particularly suitable for companies with strong brands that are able to handle complex issues of power relations and avoid exercising opportunistic behavior that could cause incentive misalignment and conflict.

\subsection{Information and communication technology}

The use of information and communication technology (ICT) has been widely recognized as the most common method of direct channel development and disintermediation. This method primarily involves the Internet (Andonova 2003, Geyskens, Gielens, and Dekimpe 2002, Sheth and Sharma 2005), but has increasingly begun to include mobile communications (Balasubramanian, Peterson, and Jarvenpaa 2002, Salo 2012). As the case studies described above demonstrate, various ICT-enabled means of disintermediation were adopted, or at least discussed, by the respondents in our research study. While SM used primarily telecommunications technologies built into robots, SMT attempted to move closer to their customers by building intelligence into CAM systems, for instance. These changes reflect the recent widespread use of ICT, which has resulted from its relatively low cost and ease of adoption (Tonta 2005). The use of ICT can also result in marketing channels that are both efficient and effective, due to increased penetration levels, low distribution costs (Geyskens et al. 2002) increased process transparency and thus enhanced customer value (Berthon et al. 2003, Michelino, Bianco, and Caputo 2008). Generally, ICT can substantially reduce the costs of both copying and distributing information (Tonta 2005), thus enabling convenient, personalized and flexible interaction that can deepen relationships with customers and facilitate knowledge transfer without the services of an intermediary (Iyer 2004, Walters 2008).

Our respondents also emphasized the need to obtain customer buy-in, because their adoption of the new working procedures is critical for the introduction of such ICT-enabled solutions. A senior manager from SM posed the question: "what supplier does the customer want to do business with?" As Sanders and colleagues put it, customers always drive distribution changes (Saunders et al. 2001), so that their buy-in is critical.

Other issues have also been mentioned in the literature. For instance, although the Internet may simplify the establishment of direct channels for industrial producers, it can also create opportunities for intermediaries to link with the same customers, leading to conflicts within marketing channels (Smith and Manna 2004, Walters 2008). In contrast, some authors state that the Internet positively influences attitudes to collaboration within a supply chain, because it can facilitate information sharing by and the integration of its members (Campo, 
Rubio, and Yaguie 2010, Michelino et al. 2008). Another negative aspect of disintermediation through ICT is the recurring conflicts that may result from excluding previously used intermediaries, such that established relationships inevitably suffer (Geyskens et al. 2002, Smith et al. 2004, Tsay and Agrawal 2004, Yue and Liu 2006). One respondent highlighted this dilemma: "some partners in the service channel are afraid that they will become redundant when we introduce the new technology". Furthermore, Saunders et al. (2001) cite implementation risks and problems, including the difficulty of foreseeing the effects of disintermediation on brand equity and customer loyalty, and the possible erosion of profits through intensified price competition (Geyskens et al. 2002).

Another important challenge is that technologies such as the Internet need to "cooperate" with other resources. These technologies are merely enablers that must operate together with organizational, relational and human resources (Michelino et al. 2008), and technology-enabled contact must often be supplemented by "human" engagement (Rosenbloom and Larsen 2003). Our empirical data largely supported the resource coordination challenge; technical processes and integration with other resources were emphasized as important challenges. In addition, the need for a new business model (e.g., new payment models and revised roles and responsibilities for handling the new business operations) was seen as an important and even critical issue when new technical solutions are adopted, such as different types of ICT tools. A manager from SMT expressed it as follows: "Everything is new and many questions remain to be addressed when we implement these changes, such as issues of ownership and payment models".

Based on the collective input from the literature and empirical findings, the following proposition can be made:

P6: Disintermediation through ICT is a disintermediation option where ICT is used to get closer to customers. This option requires significant time and other efforts to integrate new technology with other processes and resources and is applied most effectively when a company has access to the necessary technical skills, resources and tools.

\section{Discussion}

One of the starting points of this paper was the limited amount of research describing alternative ways of handling intermediaries in marketing channels for services. Accordingly, the major contributions of this study are: (1) the proposal of six disintermediation mechanisms that represent different courses of action for industrial producers to bridge the gap to their end customers; and (2) the description of challenges associated with each option. Our different perspective on disintermediation, considers not simply removing the intermediary, or using the Internet as a new channel, but more generally reversing or eradicating the problems related to intermediaries, and the subsequent inclusion of the broader management and marketing literature into our abductive study.

Essentially, our conclusion is that companies can choose between six disintermediation mechanisms which can be used in isolation, or in various combinations.

\subsection{Limitations and directions for future research}

While the six disintermediation mechanisms and their corresponding challenges drawn from the broader generic literature and the empirical data appear to be applicable in many contexts, disintermediation in industrial service supply chains entails a number of 
idiosyncrasies compared with disintermediation in other contexts. For instance, there are generally relatively few industrial customers (Jackson and Cooper 1988) and they consist of manufacturing and processing firms and distributors who buy and resell to other industries and end customers. The transactions typically involve relatively high value, and many people at different levels are involved in the interaction process over a relatively long period of time (Webster 1991: 9-10). Furthermore, the complexity of interactions and exchange relationships in industrial networks (Ford and Håkansson 2006, Henneberg, Naudé, and Mouzas 2010) can make disintermediation an even more complicated and unpredictable endeavor. Partnering or mergers and acquisitions, for instance, are not merely dyadic, but rather components in a complex and partly unpredictable structural and social change that cannot be planned exhaustively. Finally, the technological nature of many industrial companies was evident in our study and revealed clear implications for activities such as communicating with end customers. Industrial goods also reveal a relatively technological character, because they entail a comparatively high service significance before and after the sale (Jackson et al. 1988). Consequently, producers of industrial goods tend to be engineering-oriented rather than marketing-oriented, because they prefer to allocate resources to research and production, rather than to distribution (Stern, El-Ansary, and Coughlan 1996: 121). This tendency may result in introversion, an emphasis on product sales rather than on service and value-based sales, and a failure to understand customer needs. To convince end customers of the benefits of services and service-based organizational structures and business models, and to adopt a more interactive service approach aimed at providing value cocreation opportunities (Grönroos and Ravald 2011), knowledge and commitment among industrial producer's sellers and other important personnel are critical, but often lacking. The organic disintermediation option, therefore, can be particularly challenging, as can be communication and training.

There is a clear need to investigate disintermediation in other types of industries, in order to control for the effect of industry characteristics. It is likely that the results are valid primarily for similar companies and similar industries, i.e., relatively large and mature manufacturing companies involved in the development and delivery of complex products, supplemented by product-related services to industrial customers.

\section{Implications for business marketing practice}

When business-to-business companies are confronted with intermediaries between them and their customer, with whom they wish to have a close working relationship and exchange various kinds of services, they may feel threatened and uncertain in handling the situation. Intermediaries may play a fundamental role in supply chains and thus should not necessarily be treated as obstacles, but rather as extended "arms" that producers can use. In dynamic markets where customers participate actively in shaping the offering and where companies increasingly have to understand how its products and services fit into customer processes (cf. Grönroos 2006), however, the broader comprehension of disintermediation considered in this article emerges as a necessary precondition for approaching end customers. In this paper, disintermediation is viewed as an organization's adoption of various mechanisms for handling unwanted intermediaries that open up a gap between itself and its customers. The disintermediation mechanisms described here may serve as a starting point for managers in business-to-business firms, including those working in sales, marketing and strategy. The present work provides suggestions regarding different disintermediation alternatives that can enable them to move closer to their end customers and alert them to potential challenges during the adoption of different disintermediation mechanisms. 
The first disintermediation mechanism is to collaborate with the intermediary (i.e., to establish some form of partnership) to allow for the benefits of having intermediaries, while moderating the drawbacks. A second and more radical variant is to acquire the intermediary or merge with it (M\&A). A third variant is to build an alternative organization organically. While there are both similarities and differences between these alternatives, disintermediation through partnering is typically associated with challenges in the form of relationships issues, such as trust, culture, and commitment. The M\&A alternative, on the other hand, is more concerned with financial issues caused by the nature of the alternative. Finally, organic disintermediation is typically associated with internal issues such as resources and skills.

In addition to these mechanisms, there are two options aimed at countering the problems of intermediaries through indirect means such as communication and training, and providing incentives to the intermediary. Companies adopting the communication and training alternative can logically expect to devote extra effort to developing their relationship with customers and to convincing them. Various kinds of incentives can be suitable, but in addition to the challenge of designing them, attention must also be paid to broader issues of power and the impact of incentives in the short and long term.

Finally, there is a technological disintermediation option, namely disintermediation using information and communication technology. Before this alternative is chosen, producers should consider the time and other efforts that may be needed to adopt this option and to integrate the new technology with other processes and resources. While this option may be relatively quick, the integration may turn out to be time consuming, in particular if interfaces with other resources are complex and non-standardized.

\section{References}

Anderson, E. and H. Gatignon (1986). Modes of foreign entry: A transaction cost analysis and propositions. Journal of International Business Studies 17(3): 1-26.

Andonova, V. (2003). Online disintermediation. Management Research 1(3): 279-290.

Ardichvili, A., R. Cardozo, and R. Sourav (2003). A theory of entrepreneurial opportunity identification and development. Journal of Business Venturing 18(1): 105-124.

Audretsch, D. B. and M. Keilbach (2007). The theory of knowledge spillover entrepreneurship. Journal of Management Studies 44(7): 1242-1254.

Balasubramanian, S., R. A. Peterson, and S. L. Jarvenpaa (2002). Exploring the implications of m-commerce for markets and marketing. Journal of the Academy of Marketing Science 30(4): 348-361.

Berthon, P., M. Ewing, L. Pitt, and P. Naudé (2003). Understanding b2b and the web: The acceleration of coordination and motivation. Industrial Marketing Management 32(7): 553-561.

Bleeke, J. and D. Ernst (1995). Is your strategic alliance really a sale? Harvard Business Review 73(1): 97-105.

Boddy, D., C. Cahill, M. Charles, H. Fraser-Kraus, and D. Macbeth (1998). Success and failure in implementing supply chain partnering: An empirical study. European Journal of Purchasing \& Supply Management 4(2/3): 143-151.

Bowersox, D. J., D. J. Closs, and T. P. Stank (2000). Ten mega-trends that will revolutionize supply chain logistics. Journal of Business Logistics 21(2): 1-16.

Campo, S., N. Rubio, and M. J. Yagüe. (2010). Information technology use and firm's perceived performance in supply chain management. Journal of Business-to-Business Marketing 17(4): 336-364. 
Chung, C., S. C. Chatterjee, and S. Sengupta (2012). Manufacturers' reliance on channel intermediaries: Value drivers in the presence of a direct web channel Industrial Marketing Management 41(1): 40-53.

Davies, A. (2004). Moving base into high-value integrated solutions: A value stream approach. Industrial and Corporate Change 13(5): 727-756.

De Carolis, D. M., B. E. Litzky, and K. A. Eddleston (2009). Why networks enhance the progress of new venture creation: The influence of social capital and cognition. Entrepreneurship: Theory \& Practice 33(2): 527-545.

De Carolis, D. M. and P. Saparito (2006). Social capital, cognition, and entrepreneurial opportunities: A theoretical framework. Entrepreneurship: Theory \& Practice 30(1): 41-56.

Douma, M. U., J. Bilderbeek, P. J. Idenburg, and J. K. Looise (2000). Strategic alliances: Managing the dynamics of fit. Long Range Planning 33(4): 579-598.

Dubois, A. and L.-E. Gadde (2002). Systematic combining - an abductive approach to case research. Journal of Business Research 55(7): 553-560.

Duncan, T. and S. E. Moriarty (1998). A communication-based marketing model for managing relationships. Journal of Marketing 62(2): 1-13.

Dutta, S., S. P. Sarmah, and S. K. Goyal (2010). Evolutionary stability auction and supply chain contracting: An analysis based on disintermediation in the indian tea supply chains. European Journal of Operational Research 207(1): 531-538.

Dyer, J. H., P. Kale, and H. Singh (2004). When to ally and when to acquire. Harvard Business Review 82(7-8): 108-115.

Eisenhardt, K. M. (1989). Building theories from case study research. Academy of Management Review 14(4): 532-550.

Eisenhardt, K. M. and M. E. Graebner (2007). Theory building from cases: Opportunities and challenges. Academy of Management Journal 50(1): 25-32.

Ellram, L. (1990). The supplier selection decision in strategic partnerships. Journal of Purchasing ad Materials Management 26(4): 8-14.

Ford, D. and H. Håkansson (2006). Imp - some things achieved: Much more to do. European Journal of Marketing 40(3/4): 248-258.

Frazier, G. L. (1999). Organizing and managing channels of distribution. Journal of the Academy of Marketing Science 27(2): 226-240.

Geyskens, I., K. Gielens, and M. G. Dekimpe (2002). The market valuation of internet channel additions. Journal of Marketing 66(2): 102-119.

Gilliland, D. I. and D. C. Bello (2001). Channel incentives as unilateral and bilateral governance processes. Journal of Marketing Channels 8(1-2): 5-31.

Glover, D. R. (1991). Distributor attitudes toward manufacturer-sponsored promotions. Industrial Marketing Management 20(3): 241-249.

Glynn, M. S., J. Motion, and R. J. Brodie (2007). Sources of brand benefits in manufacturerreseller b2b relationships. Journal of Business \& Industrial Marketing 22(6): 400-409.

Gomes-Casseres, B. (1998). Do you really have an alliance strategy. Strategy \& Leadership 26(4): 6-11.

Grönroos, C. (2006). Adopting a service logic for marketing. Marketing Theory 6(3): 317333.

Grönroos, C. (2007) Service management and marketing: Customer management in service competition, (Third edn). Chichester: John Wiley and Sons, Ltd.

Grönroos, C. (2011). A service perspective on business relationships: The value creation, interaction and marketing interface. Industrial Marketing Management 20(2): 240247. 
Grönroos, C. and P. Helle (2010). Adopting a service logic in manufacturing: Conceptual foundation and metrics for mutual value creation. Journal of Service Management 21(5): 564-590.

Grönroos, C. and A. Ravald (2011). Service as business logic: Implications for value creation and marketing. Journal of Service Management 22(1): 5-22.

Harrigan, K. R. (1988). Joint ventures and competitive strategy. Strategic Management Journal 9(2): 141-158.

Henneberg, S., P. Naudé, and S. Mouzas (2010). Sense-making and management in business networks - some observations, considerations, and a research agenda. Industrial Marketing Management 39(3): 355-360.

Hoffman, W. H. and W. Schaper-Rinkel (2001). Acquire or ally? - a strategy framework for deciding between acquisition and cooperation. Management International Review 41(2): 131-159.

Honjo, Y. (2000). Business failure of new firms: An empirical analysis using a multiplicative hazards model. International Journal of Industrial Organization 18(4): 557-574.

Huizingh, E. K. R. E. (2002). Towards successful e-business strategies: A hierarchy of three management models. Journal of Marketing Management 18(7/8): 721-747.

Inkpen, A. C. (1996). Creating knowledge through collaboration. California Management Review 39(1): 123-140.

Ireland, R. D., M. A. Hitt, and D. Vaidyanath (2002). Alliance management as a source of competitive advantage. Journal of Management 28(3): 413-446.

Iyer, G., R. (2004). Internet-enabled linkages: Balancing strategic considerations with operational efficiencies in business-to-business marketing. Journal of Business-toBusiness Marketing 11(1-2): 35-59.

Jackson, R. W. and P. D. Cooper (1988). Unique aspects of marketing industrial services. Industrial Marketing Management 17(2): 111-118.

Johnson, J. L. and G. S. Black (1996). The effects of relationalism and supplier replaceability on industrial distribution channel outcomes. Journal of Marketing Channels 5(2): 2544.

Karlsson, C. (2003). The development of industrial networks - challenges to operations management in an extraprise. International Journal of Operations and Production Management 23(1): 44-61.

Kidd, P. S. and M. B. Parshall (2000). Getting the focus and the group: Enhancing analytical rigor in focus group research. Qualitative Health Research 10(3): 293-308.

Kindström, D., C. Kowalkowski, and F. Nordin (2012). Visualizing the value of servicebased offerings: Empirical findings from the manufacturing industry. Journal of Business \& Industrial Marketing 27(7): 538-546.

Lambert, D., M. Emmelhainz, and J. Gardner (1996). Developing and implementing supply chain partnerships. International Journal of Logistics Management 7(2): 1-18.

Lancioni, R. A., M. F. Smith, and T. A. Oliva (2000). The role of the internet in supply chain management. Industrial Marketing Management 29(1): 45-56.

Llopis, J., J. Gasco, and R. Gonzalez (2006). Training customers: An organizational experience. Industrial and Commercial Training 38(2): 78-85.

Maloni, M. and W. C. Benton (2000). Power influences in the supply chain. Journal of Business Logistics 21(1): 49-73.

Maloni, M. J. and W. C. Benton (1997). Supply chain partnerships: Opportunities for operations research. European Journal of Operational Research 101(3): 419-429.

Matthyssens, P. and K. Vandenbempt (2008). Moving from basic offerings to value-added solutions: Strategies, barriers and alignment. Industrial Marketing Management 37(3): 316-328. 
Mcdonald, F. (1999). The importance of power in parthership relationships. Journal of General Management 25(1): 131-149.

Mentzer, J. T., S. Min, and Z. G. Zacharia (2000). The nature of interfirm partnering in supply chain management. Journal of Retailing 76(4): 549-568.

Michelino, F., F. Bianco, and M. Caputo (2008). Internet and supply chain management: Adoption modalities for italian firms. Management Research News 31(5): 359-374.

Mittermeyer, S. A., J. A. Njuguna, and J. R. Alcock (2011). Product-service systems in health care: Case study of a drug-device combination. The International Journal of Advanced Manufacturing Technology 52(9-12): 1209-1221.

Mohr, J. and R. E. Spekman (1994). Characteristics of partnership success: Partnership attributes, communication behaviour, and conflict resolution techniques. Strategic Management Journal 15(2): 135-152.

Narayanan, V. G. and A. Raman (2004). Aligning incentives in supply chains. Harvard Business Review 82(11): 94-102.

Neck, H. M., G. D. Meyer, B. Cohen, and A. C. Corbett (2004). An entrepreneurial system view of new venture creation. Journal of Small Business Management 42(2): 190-208.

Nordin, F. (2005) Externalising services: Walking a tightrope between industrial and service logics. Doctoral Dissertation, Stockholm School of Economics.

Nordin, F. (2006). Identifying intraorganisational and interorganisational alliance conflicts - a longitudinal study of an alliance pilot project in the high technology industry. Industrial Marketing Management 35(2): 116-127.

Normann, R. (2000) Service management: Strategy and leadership in the service business, (3rd edn). Chichester: John Wiley and Sons Ltd.

Normann, R. (2001) Reframing business - when the map changes the landscape. Chichester: John Wiley \& Sons, Ltd.

Osborne, R. N. and C. C. Baughn (1990). Forms of interorganizational governance for multinational alliances. Academy of Management Journal 33(3): 503-519.

Ottesen, G. G. and K. Grønhaug (2005). Positive illusions and new venture creation: Conceptual issues and an empirical illustration. Creativity and Innovation Management 14(4): 405-412.

Paiola, M., H. Gebauer, and B. Edvardsson (2012). Service business development in small to medium-sized equipment manufacturers. Journal of Business-to-Business Marketing 19(1): 33-66.

Rangan, V. K. and G. T. Bowman (1992). Beating the commodity magnet. Industrial Marketing Management 21(3): 215-224.

Roberts, E. B. and C. A. Berry (1985). Entering new businesses: Selecting strategies for success. Sloan Management Review 26(3): 3-17.

Rosenbloom, B. and T. Larsen (2003). Communication in international business-to-business marketing channels. Industrial Marketing Management 32(4): 309-315.

Salo, J. (2012). The role of mobile technology in a buyer-supplier relationship: A case study from the steel industry. Journal of Business \& Industrial Marketing 27(7): 554-563.

Saunders, P., H. Brown, R. Brucker, and R. Bloomingdale (2001). Disintermediation and the changing distribution landscape. Marketing Management Journal 11(2): 50-57.

Schutjens, V. a. J. M. and E. Wever (2000). Determinants of new firm success. Papers in Regionals Science 79(2): 135-159.

Shane, S. (2000). Prior knowledge and the discovery of entrepreneurial opportunities. Organization Science 11(4): 448-469.

Shapiro, J. M., N. C. J. Romano, and B. Mittal (2004). Emergent internet technology applications for relationship marketing. Journal of Relationship Marketing 2(3-4): 85108. 
Sheth, J. N. and A. Sharma (2005). International e-marketing: Opportunities and issues. International Marketing Review 22(6): 611-622.

Silverman, D. (1993) Interpreting qualitative data. London: Sage.

Smith, A. D. and D. R. Manna (2004). Strategic disintermediation within the context of ecommerce: The effect on distributors and re-sellers. Journal of American Academy of Business 5(1/2): 374-380.

Stern, L. W., A. I. El-Ansary, and A. T. Coughlan (1996) Marketing channels. Upper Saddle River, NJ: Prentice Hall.

Stewart, D. W. and P. N. Shamdasani (1990) Focus groups: Theory and practice. Newbury Park: Sage Publications.

Stremersch, S., S. Wuyts, and R. T. Frambach (2001). The purchasing of full-service contracts: An exploratory study within the industrial maintenance market. Industrial Marketing Management 30(1): 1-12.

Tate, K. (1996). The elements of a successful logistics partnership. International Journal of Physical Distribution \& Logistics Management 26(3): 7-13.

Tonta, Y. (2005). Internet and electronic information management. Information Services \& Use 25(1): 3-12.

Tsay, A. A. and N. Agrawal (2004). Channel conflict and coordination in the e-commerce age. Productions and Operations Management 13(1): 93-110.

Tuli, K. R., A. K. Kohli, and S. G. Bharadwaj (2007). Rethinking customer solutions: From product bundles to relational processes. Journal of Marketing 71(3): 1-17.

Walsh, G., H. Evanschitzky, and M. Wunderlich (2008). Identification and analysis of moderation variables: Investigating the customer satisfaction-loyalty link. European Journal of Marketing 42(9/10): 977-1004.

Walters, P. G. P. (2008). Adding value in global b2b supply chains: Strategic directions and the role of the internet as a driver of competitive advantage. Industrial Marketing Management 37(1): 59-68.

Watson, K., S. Hogarth-Scott, and N. Wilson (1998). Small business start-ups: Success factors and support implications. International Journal of Entrepreneurial Behaviour \& Research 4(3): 217-238.

Webster, F. E. J. (1991) Industrial marketing strategy, (3 edn). New York: John Wiley \& Sons.

Williamson, O. E. (1979). Transaction cost economics: The governance of contractual relations. Journal of Law and Economics 22(2): 233-261.

Yin, R. K. (1994) Case study research: Design and methods, (Second edn). London: Sage.

Yue, X. and J. Liu (2006). Demand forecast sharing in a dual-channel supply chain. European Journal of Operational Research 174(1): 646-667.

Åhlström, P. and F. Nordin (2006). Problems of establishing service supply relationships: Evidence from a high-tech manufacturing company. Journal of Purchasing and Supply Management 12(2): 75-89. 
FIGURE 1 A conceptual model of the research

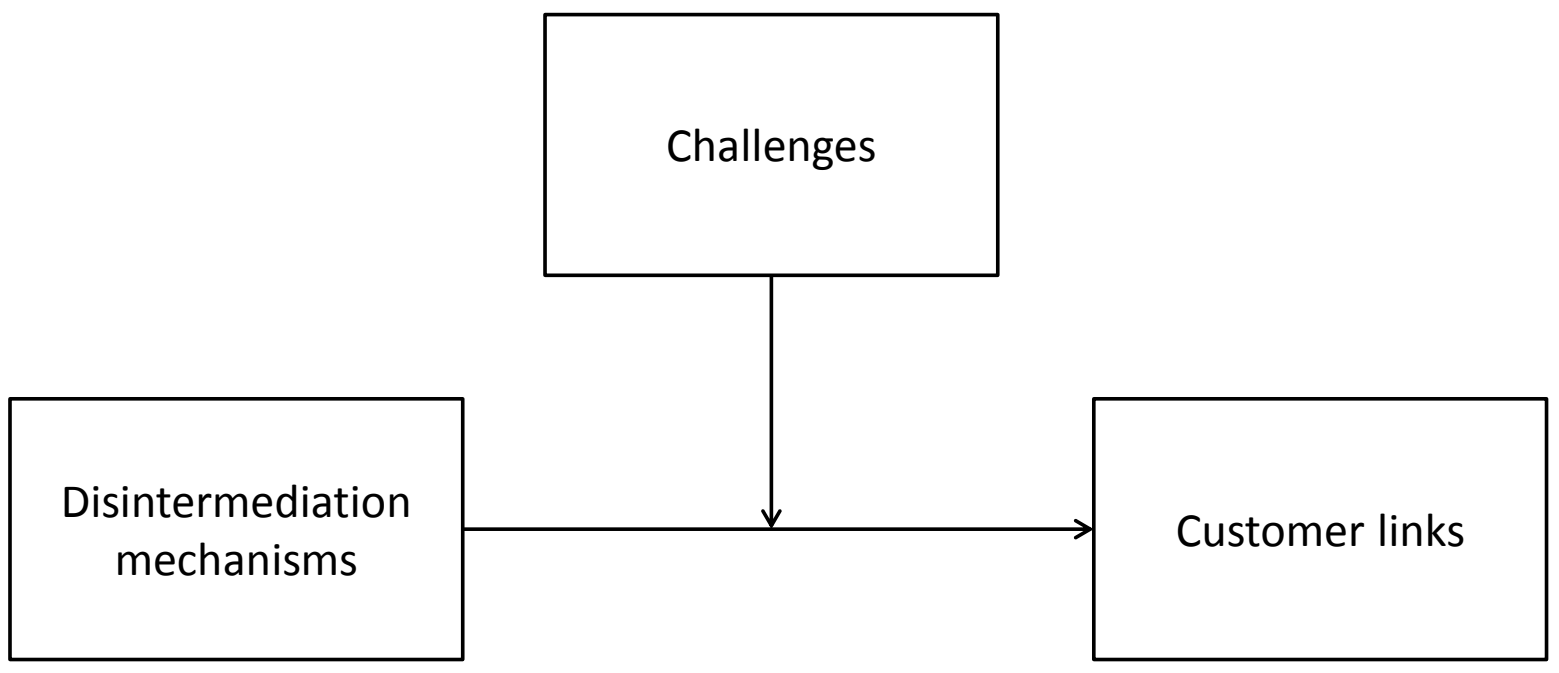


TABLE 1 Problems and primary disintermediation mechanisms of the cases

\begin{tabular}{|r|l|l|l|l|}
\hline Case & Rotating systems (RS) & Smooth Units (SU) & $\begin{array}{l}\text { Sharp Machine Tools } \\
\text { (SMT) }\end{array}$ & Smart Machines (SM) \\
\hline $\begin{array}{r}\text { Problem } \\
\text { experienced by provider } \\
\text { the prof }\end{array}$ & $\begin{array}{l}\text { For some time, customer } \\
\text { relationships have been lost } \\
\text { to various third-party actors } \\
\text { in the fragmented property } \\
\text { business. }\end{array}$ & $\begin{array}{l}\text { End customer shifting to } \\
\text { lower-cost service provider, } \\
\text { because of financial } \\
\text { problems. }\end{array}$ & $\begin{array}{l}\text { The predicted loss of } \\
\text { previously good customer } \\
\text { relationships, because of } \\
\text { technological developments } \\
\text { and cost pressure. }\end{array}$ & $\begin{array}{l}\text { The predicted loss of } \\
\text { previously good customer } \\
\text { relationships and entry of } \\
\text { third-party actors, because of } \\
\text { improved reliability and } \\
\text { commoditization of robots. }\end{array}$ \\
\hline $\begin{array}{r}\text { Primary } \\
\text { disintermediation } \\
\text { mechanism used } \\
\text { by the provider }\end{array}$ & $\begin{array}{l}\text { Communication about their } \\
\text { offering to convince } \\
\text { potential customers and } \\
\text { partners. }\end{array}$ & $\begin{array}{l}\text { Partnering with lower-cost } \\
\text { company. }\end{array}$ & $\begin{array}{l}\text { Together with CAM } \\
\text { suppliers, introducing a new } \\
\text { ICT-based application as a } \\
\text { means of improving value } \\
\text { and connecting with } \\
\text { customers. }\end{array}$ & $\begin{array}{l}\text { Communication closely } \\
\text { linked to their ICT-based } \\
\text { remote service. }\end{array}$ \\
\hline
\end{tabular}


TABLE II Summary of disintermediation mechanisms and their attendant challenges.

\begin{tabular}{|c|c|c|}
\hline Disintermediation mechanism & Challenges & Illustrative quotes \\
\hline $\begin{array}{l}\text { Strategic partnering: A flexible way of } \\
\text { improving customer value by } \\
\text { collaborating closely with the } \\
\text { intermediary. }\end{array}$ & $\begin{array}{l}\text { Intermediary relationship } \\
\text { issues (concerned with, e.g., } \\
\text { trust, culture, and } \\
\text { commitment). }\end{array}$ & $\begin{array}{l}\text { (1) "We have a strong brand and our new partner intends to take } \\
\text { advantage of it. But it's fine with us; they have complementary skills", } \\
\text { (2) "It is not easy to find a true partnership where all parties are equally } \\
\text { open", (3) "We could not work together, because there were many } \\
\text { things that clashed, mostly philosophy and culture". }\end{array}$ \\
\hline $\begin{array}{l}M \& A \text { : A radical way of taking control } \\
\text { of the channel by merging with, or } \\
\text { buying the external intermediary. }\end{array}$ & $\begin{array}{l}\text { Financial issues (e.g., direct } \\
\text { costs and integration costs) and } \\
\text { intermediary-relationship } \\
\text { issues (concerned with, e.g., } \\
\text { trust and culture). }\end{array}$ & $\begin{array}{l}\text { "Buying service companies is not an option, we rather cooperate. Our } \\
\text { idea is to add value on our own, not just buying others", (2) "If one } \\
\text { looks at the industry, there is no company large enough to buy, nothing } \\
\text { lucrative in that way", (3) "A purchase would clash with the culture, } \\
\text { process, and thoughts". }\end{array}$ \\
\hline $\begin{array}{l}\text { Organic: An intrapreneurial option } \\
\text { based on internal resources and skills } \\
\text { and the development of an in-house } \\
\text { alternative to the external intermediary. }\end{array}$ & $\begin{array}{l}\text { Internal issues, such as } \\
\text { resources and skills. }\end{array}$ & $\begin{array}{l}\text { (1) "There is a lack of competence in our subsidiaries and building it } \\
\text { internally is difficult, expensive, and time-consuming", (2) "They have } \\
\text { tried for years and failed. Lack of expertise can be a cause", (3) "The } \\
\text { biggest challenge is finding enough of our own resources, people who } \\
\text { can deliver". }\end{array}$ \\
\hline $\begin{array}{l}\text { Communication and training: A } \\
\text { straightforward option of } \\
\text { disintermediation by influencing the } \\
\text { customer and exchanging information } \\
\text { and instructions. }\end{array}$ & Customer relationship issues. & $\begin{array}{l}\text { (1) "We have had difficulties reaching out to customers this time. I think } \\
\text { it is a matter of communication and training", (2) "How do we } \\
\text { communicate value and how can we get paid for the benefits the end } \\
\text { customer experience?", (3) "Another critical challenge is educating } \\
\text { customers." }\end{array}$ \\
\hline $\begin{array}{l}\text { Incentives: An ingenious system to } \\
\text { make the intermediary itself act } \\
\text { appropriately by using different sets of } \\
\text { incentives and bonuses. }\end{array}$ & $\begin{array}{l}\text { Strategic or power-related } \\
\text { issues. }\end{array}$ & $\begin{array}{l}\text { (1) "We apply bonuses and incentives, we encourage them to sell on our } \\
\text { behalf, they would get the profits, we would get the benefits such as cost } \\
\text { control", (2) "We have no legal power, only social power", (3) "The } \\
\text { reseller realizes they can also sell various services connected to our } \\
\text { portfolio if they sell our products, and that we support this" }\end{array}$ \\
\hline $\begin{array}{l}\text { ICT: An efficient technology-based } \\
\text { (e.g., internet and telematics) } \\
\text { alternative for the technically } \\
\text { knowledgeable. }\end{array}$ & $\begin{array}{l}\text { Technological and operational } \\
\text { issues. }\end{array}$ & $\begin{array}{l}\text { (1) "The new application also has to fit with our other resources, } \\
\text { applications, systems and processes.", (2) Some technical issues also } \\
\text { need to be addressed", (3) "When you get the processes in place, it is an } \\
\text { extremely useful tool, but all parts must work together consistently" }\end{array}$ \\
\hline
\end{tabular}

